\title{
INFLUENCES OF CLIMATE CHANGE ON BEACH PROFILE
}

\author{
Kentaro Hayashi ${ }^{1}$, Nobuhito Mori ${ }^{2}$, Hajime Mase², Yoshiaki Kuriyama ${ }^{3}$, \\ and Nobuhisa Kobayashi ${ }^{4}$
}

\begin{abstract}
The influences of climate change due to global warming have been estimated on not only sea level rise but also wave characteristics such as height or energy flux. In this study, the characteristics of medium and long term beach profile change is investigated based on the observed beach profile data at HORS for past 24 years and the relationship between the wave characteristics observed at Kashima port and the climate indexes. In order to estimate the influences of the medium and long term wave characteristic change, a theory is introduced based on equilibrium beach profile with wave parameter, which is theoretically based on sediment characteristic. Moreover, the validation of the theory is evaluated based on the observed beach profile data and wave data.
\end{abstract}

Keywords: climate change, equilibrium beach profile, beach profile change

\section{INTRODUCTION}

The climate change due to global warming may cause not only sea level rise but also storm intensification. Regarding to recent studies, Mori et al. (2009) indicated that the averaged wave conditions were evaluated quantitatively and had big differences in areas. Mori et al. (2010) computed future surface winds and waves using the atmospheric general circulation model and global wave model. Extreme wave heights were predicted to increase but mean wave heights were predicted to decrease around Japan in future climate. Beach erosion may become more severe due to the combined effects of sea level rise and storm intensification.

In the long term effect on beach erosion with climate change, Bruun's Law (1962) has been used. Bruun's expression contains the shoreline change due to only sea level rise and the trend. Thinking of the medium and long term change, the wave characteristics should be considered with a range of annual and mid-long term.

In this study, in order to investigate the influences of the wave condition change due to climate change, the characteristics of long term beach profile change and the relationship between beach profile change and wave condition are analyzed, based on the surveyed beach profile data for many years. Moreover, in order to study the effect on beach profile in the future, an equilibrium beach profile equation is expressed by using a coefficient with wave conditions, not by a coefficient with sediment characteristics and the validation. Finally, the cross-shore beach processes are examined using the numerical model, CSHORE (Kobayashi et al. 2008).

\section{STUDY SITE}

At Hazaki Coast in Ibaraki Prefecture is facing the Pacific Ocean. Kashima Port constructed in 1960s and finished in 1970s. Hazaki Oceanographical Research Station (HORS) has been continuously surveying the beach profile along their observation pier since 1986. The beach profile has been measured daily along the 427-m long concrete pier. The basic level is set as the construction basic level at Hazaki fishing port (D.L.0.0m= T.P.-0.690m). The tide condition is set based on the same basic level and the representative levels are set as H.W.L. $=$ D.L. $+1.252 \mathrm{~m}$, M.W.L. $=$ D.L $+0.651 \mathrm{~m}$, and L.W.L.=D.L.-0.196m. Figure 1 shows the location of the research facility.

In this study, total 1288 weekly profiles, which were surveyed from March 1986 to December 2010, are used to investigate the relationship between representative wave height and beach profile. Figure 2 describes the all beach profiles and the averaged beach profile. Under the M.W.L., the beach profiles have the wider range in comparison with that above water. This means the sand bar is frequently deformed and moved. On the other hand, he averaged beach profile under the M.W.L. does not have sand bar formation and relatively mild slope.

\footnotetext{
${ }^{1}$ Engineering Division, Alpha Hydraulic Engineering Consultants Co., Ltd. Tokyo Branch, 2-7-9 Higashikanda Chiyoda-ku, Tokyo, 101-0031, JAPAN

${ }^{2}$ DPRI, Kyoto University, Kyoto, 611-0011, JAPAN

${ }^{3}$ Port and Airport Research Institute, Kanagawa, 239-0826, JAPAN

${ }^{4}$ CACR, University of Delaware, Newark, DE, 19716, USA
} 


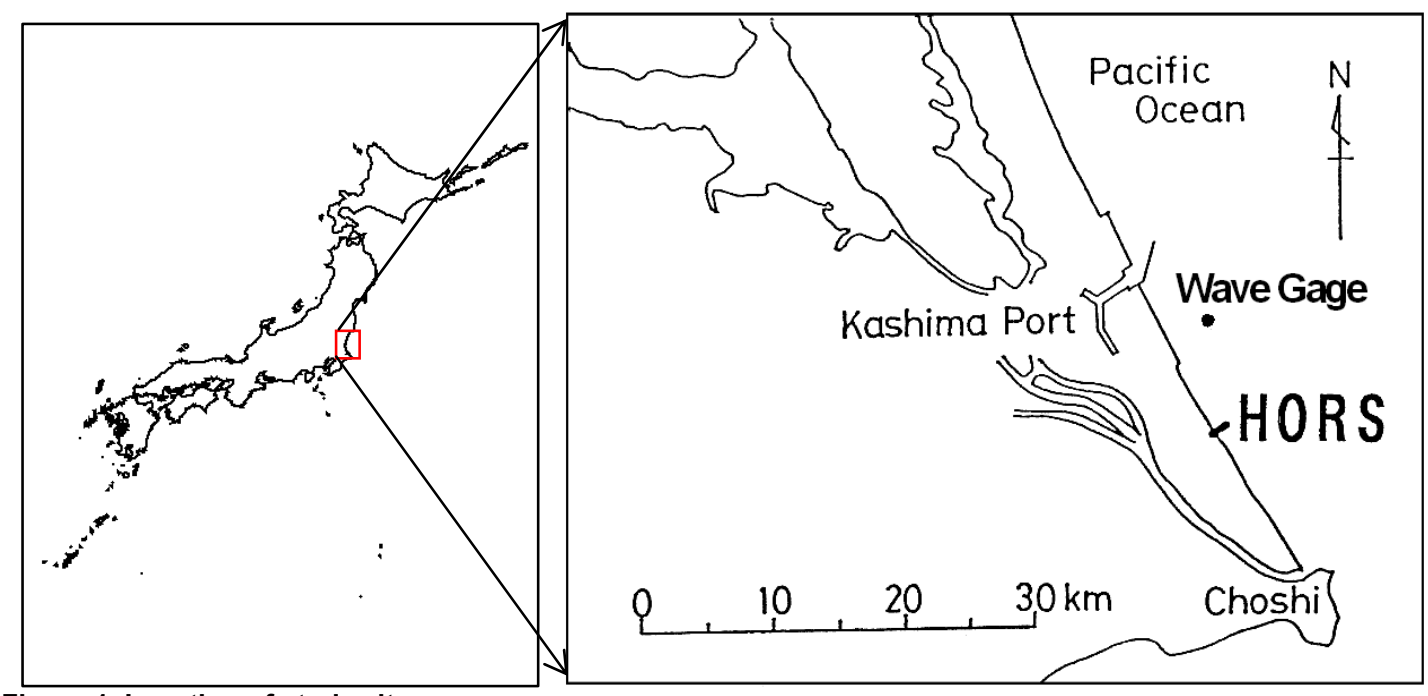

Figure 1. Location of study site

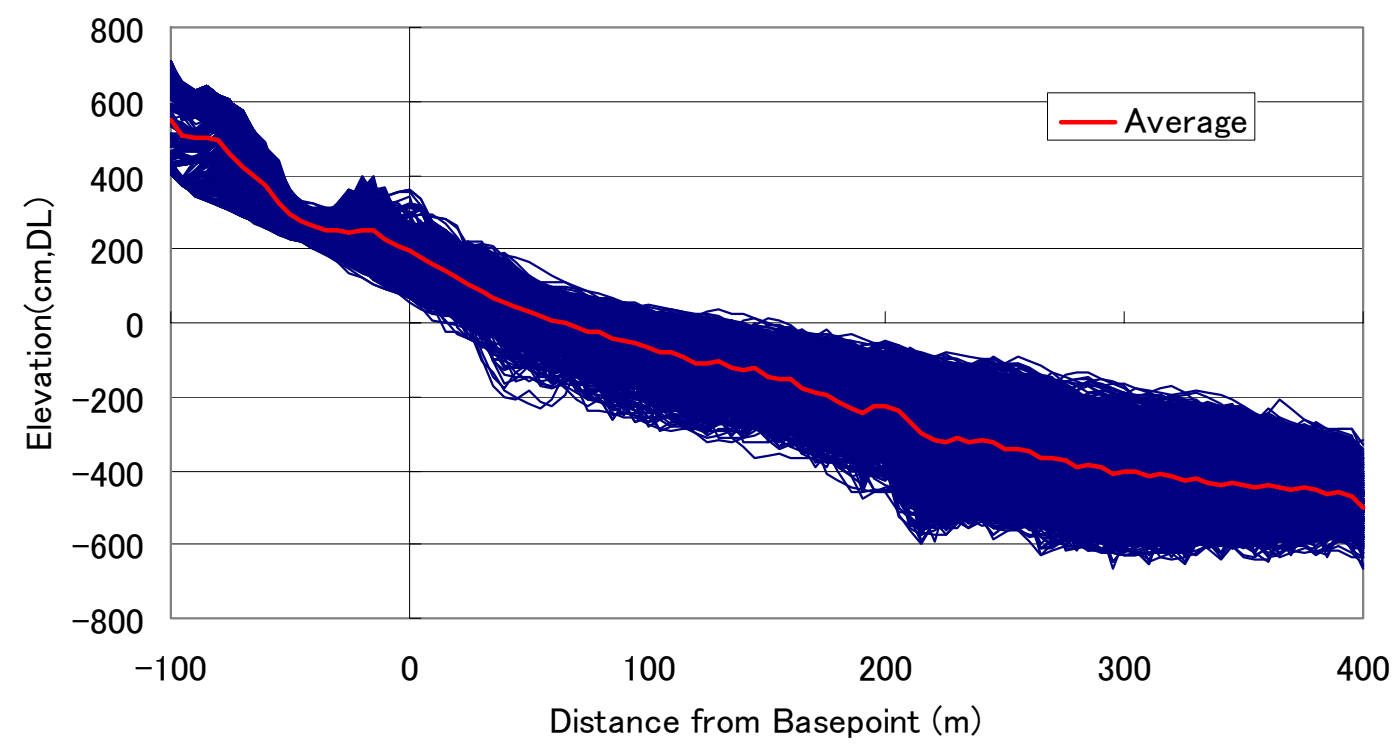

Figure 2. Beach profiles and averaged beach profile

\section{MID-LONG TERM TREND}

Wave Characteristic

There is a long term wave observation station near the HORS, which is called Kashima port (NOWPAHS, water depth 24m). The location is described in Figure 1. In this study, the wave 2 hourly data (the significant wave height and wave period), observed at Kashima port from 1991 to 2007, is used to understand the wave characteristics along the Hazaki coast. Unfortunately the data from 2008 to 2009 was not collected due to mechanical trouble.

Figure 3 presents the annual wave energy flux and the acquisition rate of wave data in order to understand the longitudinal change on the wave energy flux. From 1991 to 1995, the wave energy flux is not reliable because of the low acquisition rate. It is not clear that the trend of wave energy flux has obvious. However, the wave energy could be increasing in the long term trend.

Figure 4 displays the trends of seasonal wave energy flux. The obvious characteristic is the energy flux in summer is lower than the others. The energy flux in autumn increases in several times could have been had the influences of typhoon. The energy flux in winter could have been had the influences of low pressure. 


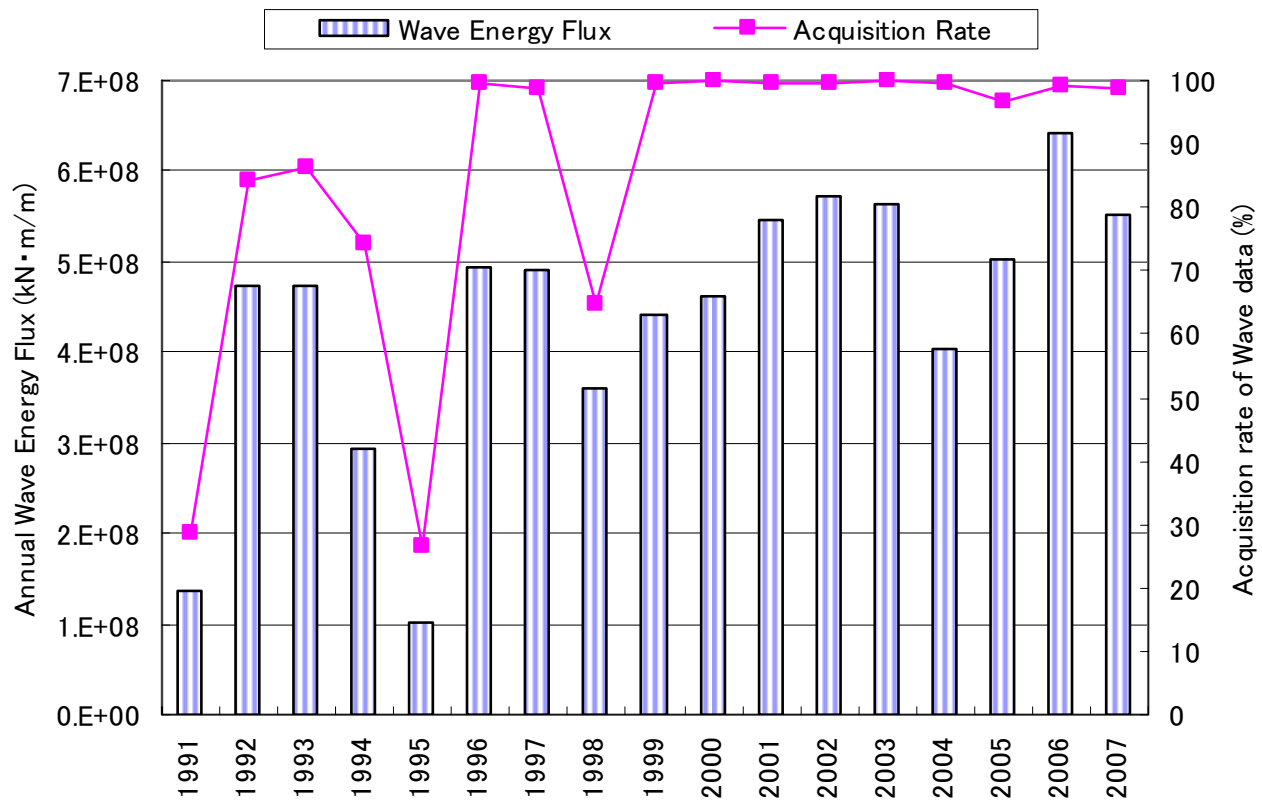

Figure 3. Annual wave energy flux and acquisition rate

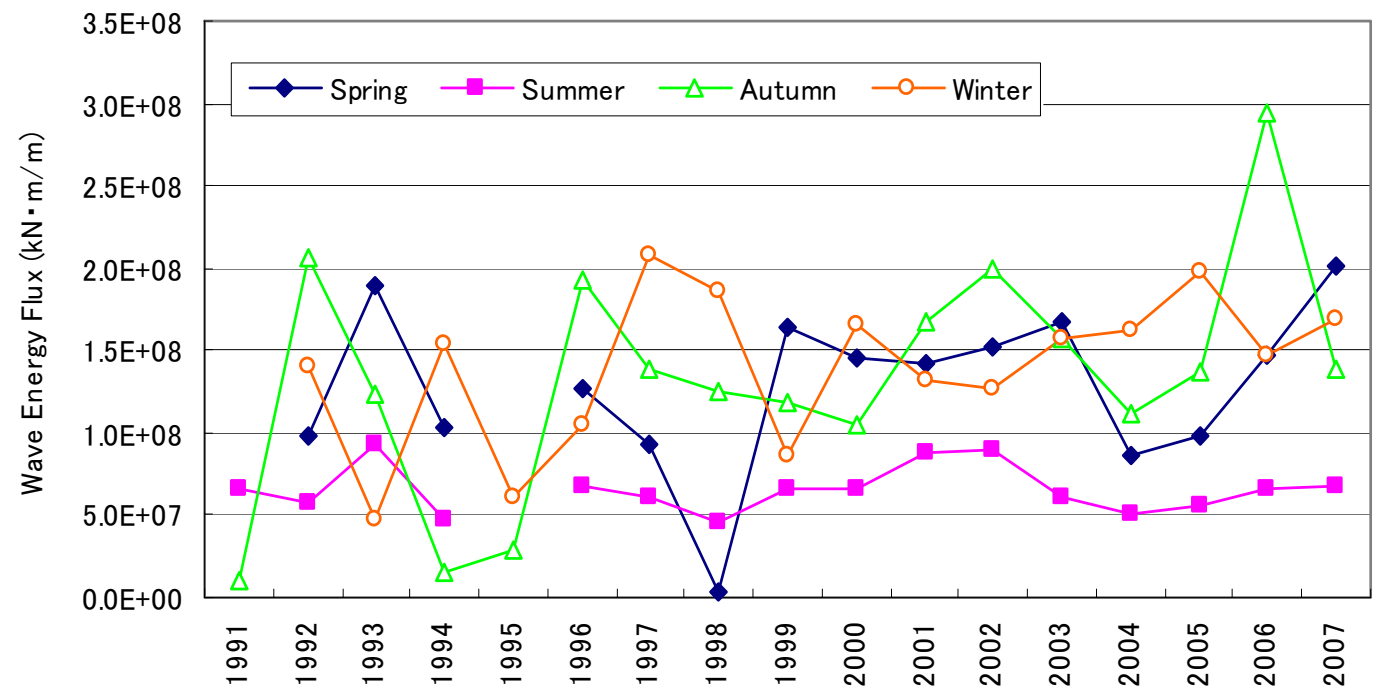

Figure 4. Seasonal wave energy flux

\section{Tide Characteristic}

There is a long term tide observation station near HORS which is called Choshi fishery port located $15 \mathrm{~km}$ south from HORS. The location is described in Figure 1. Based on the hourly data observed from 1985 to 2009, the long-term trend is investigated and the result is shown in Figure 5. As the result of the single regression analysis of annual averaged data, the sea level has slightly increasing trend, which is $0.7 \mathrm{~cm} /$ year. 


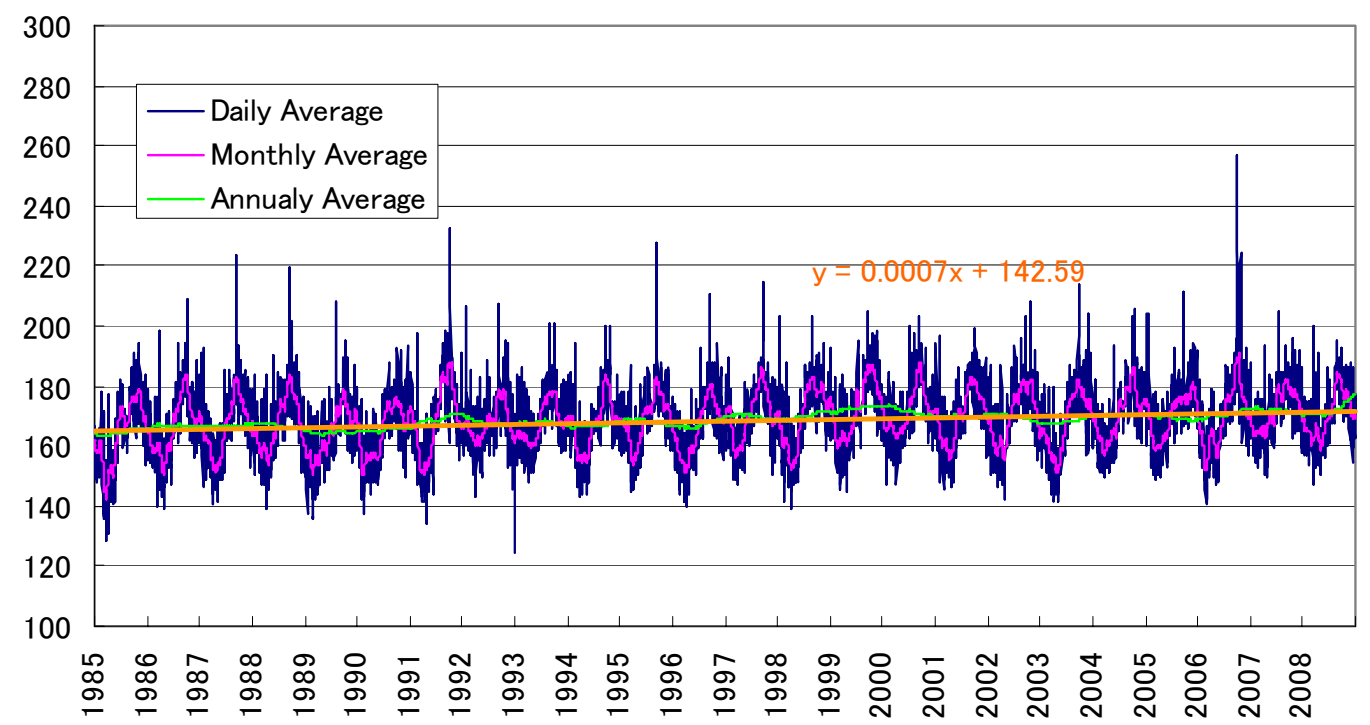

Figure 5. Averaged sea levels

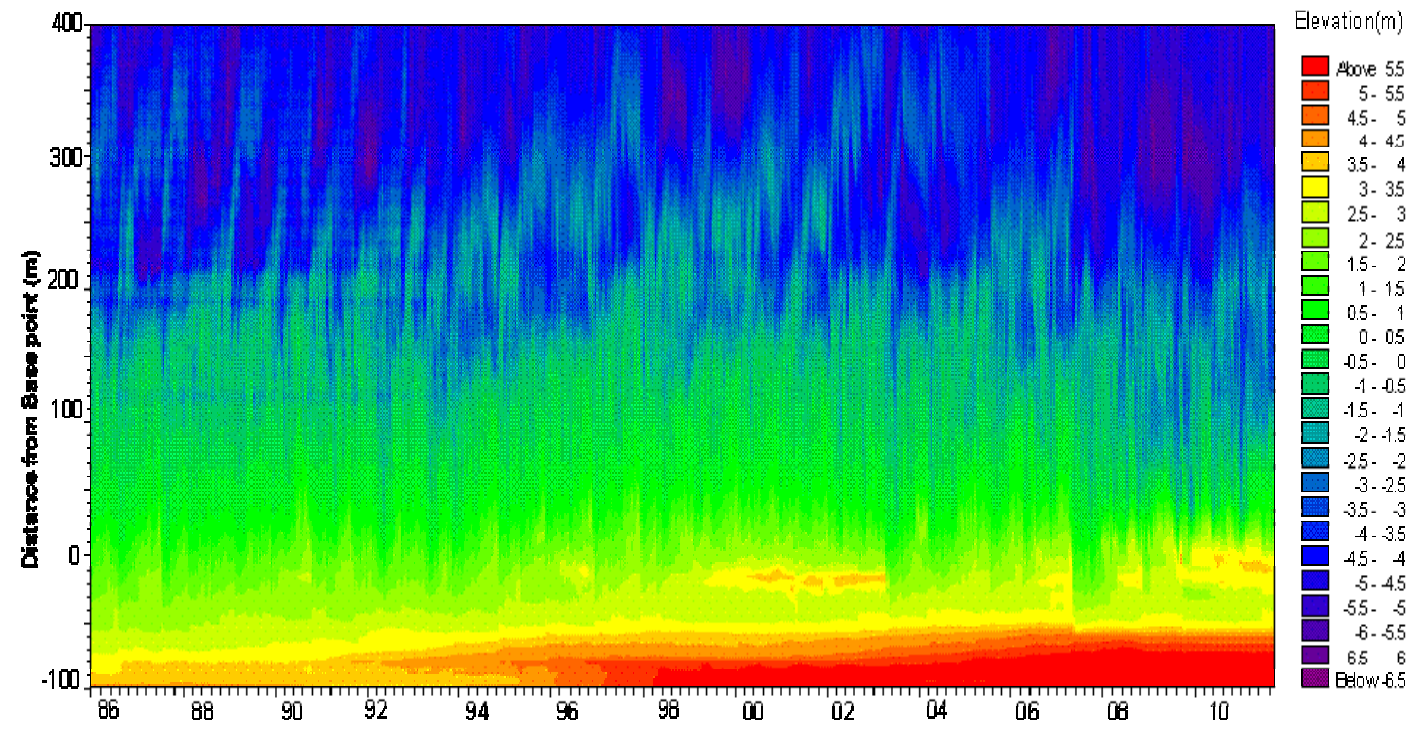

Figure 6. Space-time map of surveyed beach profiles

\section{Beach Profile Trend}

Figure 6 describes a space-time map of variation of weekly beach profile. The $x$-axis means the time and the $y$-axis means the distance from the survey base point. The low side is landward. As shown in the color legend, since 1996 the berm behind the fore shore has been developed and the bar deformation could have several years interval. However, the relationship between the bar and berm deformation is not clear.

As the next step, the change in time of the cross-sectional area is analyzed and the result is shown in Figure 7. In this study, the bottom limit is set up as D.L.-700 cm based on the lowest profile elevation during the observation term. The total area does not have the flat trend. This is because this analysis can not remove the effect of offshore limitation. As the result, the total beach profile area has increasing trend from 1986 to 1999 and decreasing trend from 1999 to 2010 . The volumes below and above MSL has similar trend, but recently that below the MSL has decreasing trend. Figure 8 shows the seasonal cross-sectional volume changes. It is hard to say that other three seasons have the obvious trend. That in summer has gentle change relatively and increasing trend. 
Dean (1977) proposed the equilibrium beach profile theory based on the wave energy dissipation. The equilibrium beach profile is expressed by the coefficient $A\left(\mathrm{~m}^{1 / 3}\right)$, which is related to the median grain size. The averaged beach profile at Hazaki coast is applied to this theory. The median grain size is $0.18 \mathrm{~mm}$, which is reported by Suzuki and Kuriyama (2008). According to the recommended table of A value, proposed by Dean et al (2001), the recommended A value is supposed to be $0.0936\left(\mathrm{~m}^{1 / 3}\right) . \mathrm{In}$ this study, the equilibrium beach profile is applied at M.S.L. as the water depth is the beginning point. Figure 9 shows the comparison between the averaged beach profile and the calculated equilibrium beach profile. The equilibrium beach profile can be reasonable fit with the averaged beach profile above $2 \mathrm{~m}$ depth, but below $2 \mathrm{~m}$ water depth underestimated.

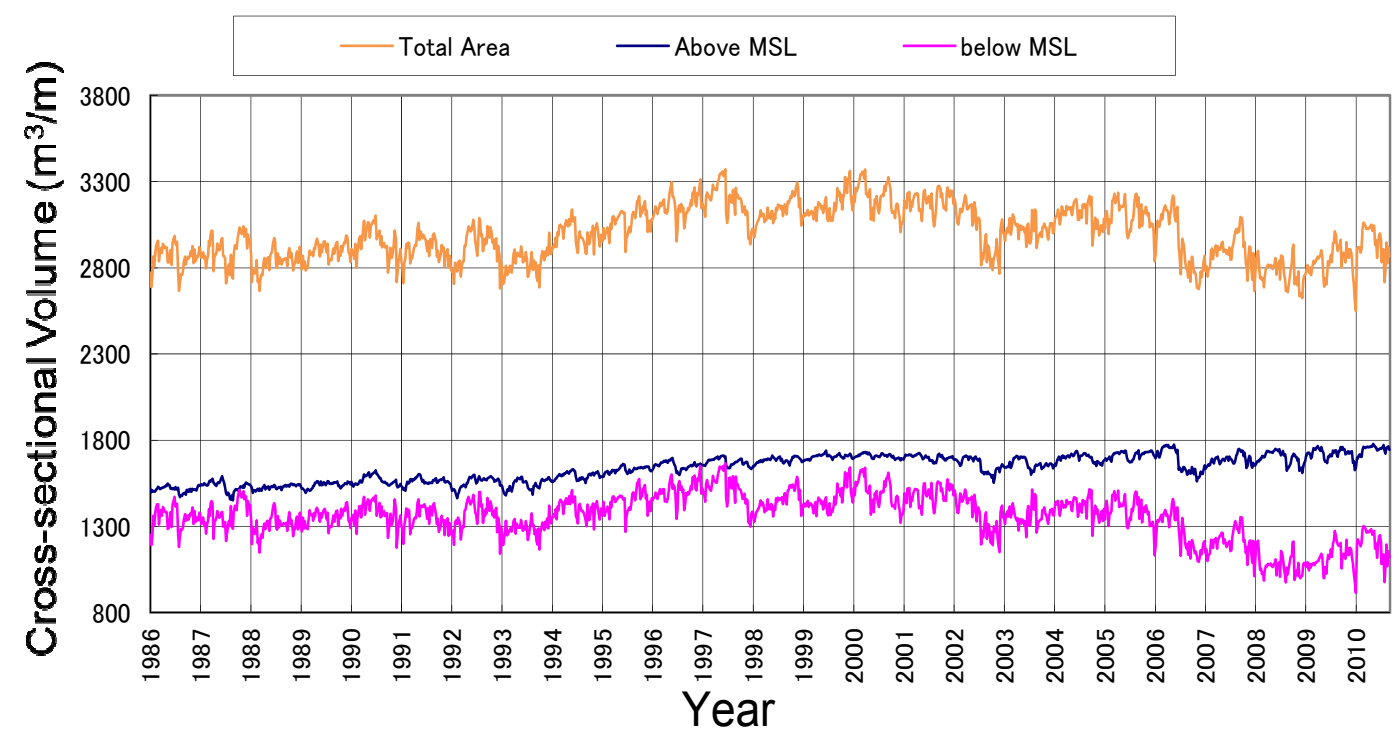

Figure 7. Time-series of cross-sectional volume

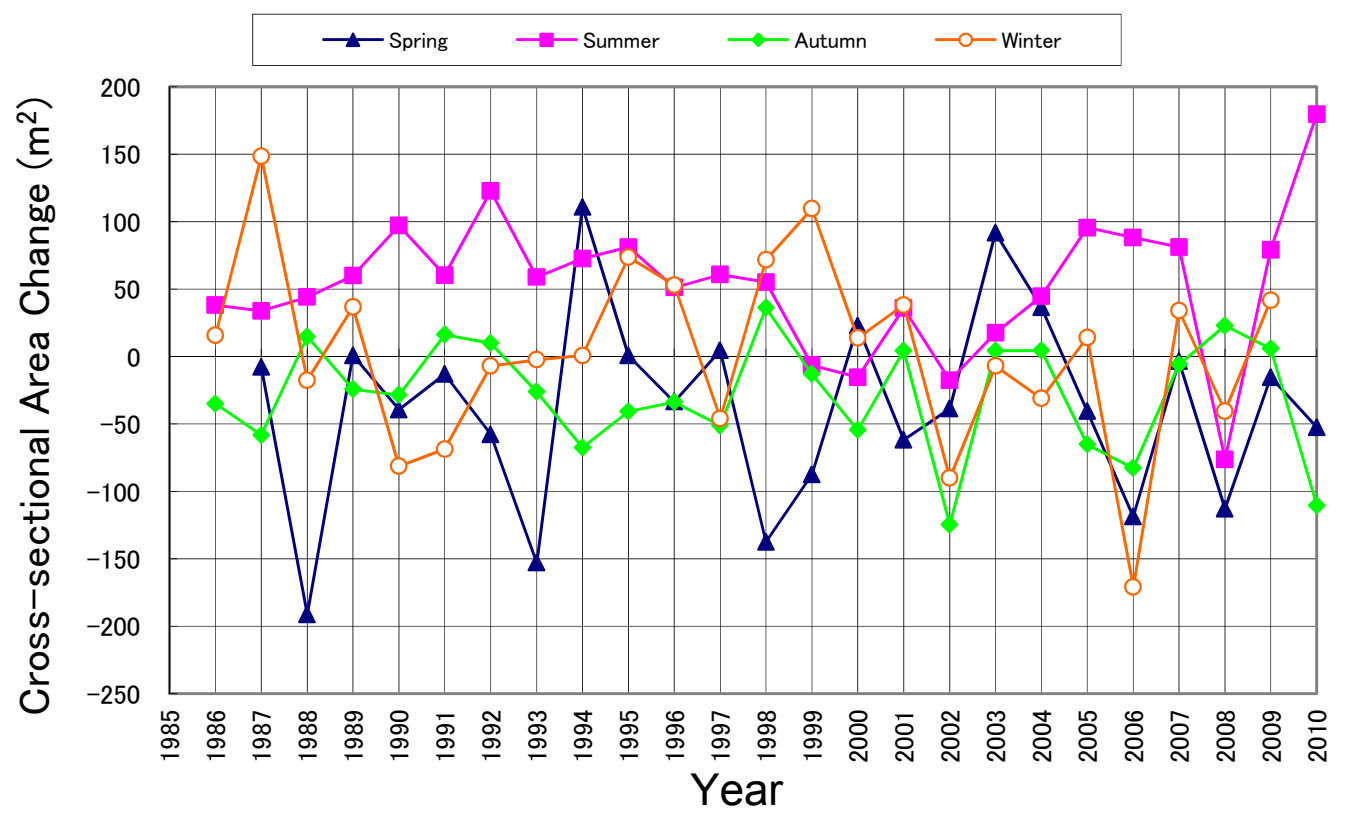

Figure 8. Seasonal change in cross-sectional area 
$A$ value could be changed not only annually but also seasonally. Therefore, the equilibrium beach profile theory is applied to 3-months (seasonal) and annual averaged beach profile with the least square method at M.S.L. elevation and the result shows in Figure 10. As the result, the summer has relatively lower value and the there is not much differences between other seasons. From 1986 to 1994, the estimated $A$ value has almost flat trend. On the other hand, from 1994 to 1999 (Term2) the estimated A value has a decreasing trend and from 1999 to 2010 (Term3) that has an increasing trend. This means Term 2 has an erosion trend and Term 3 has accretion trend.

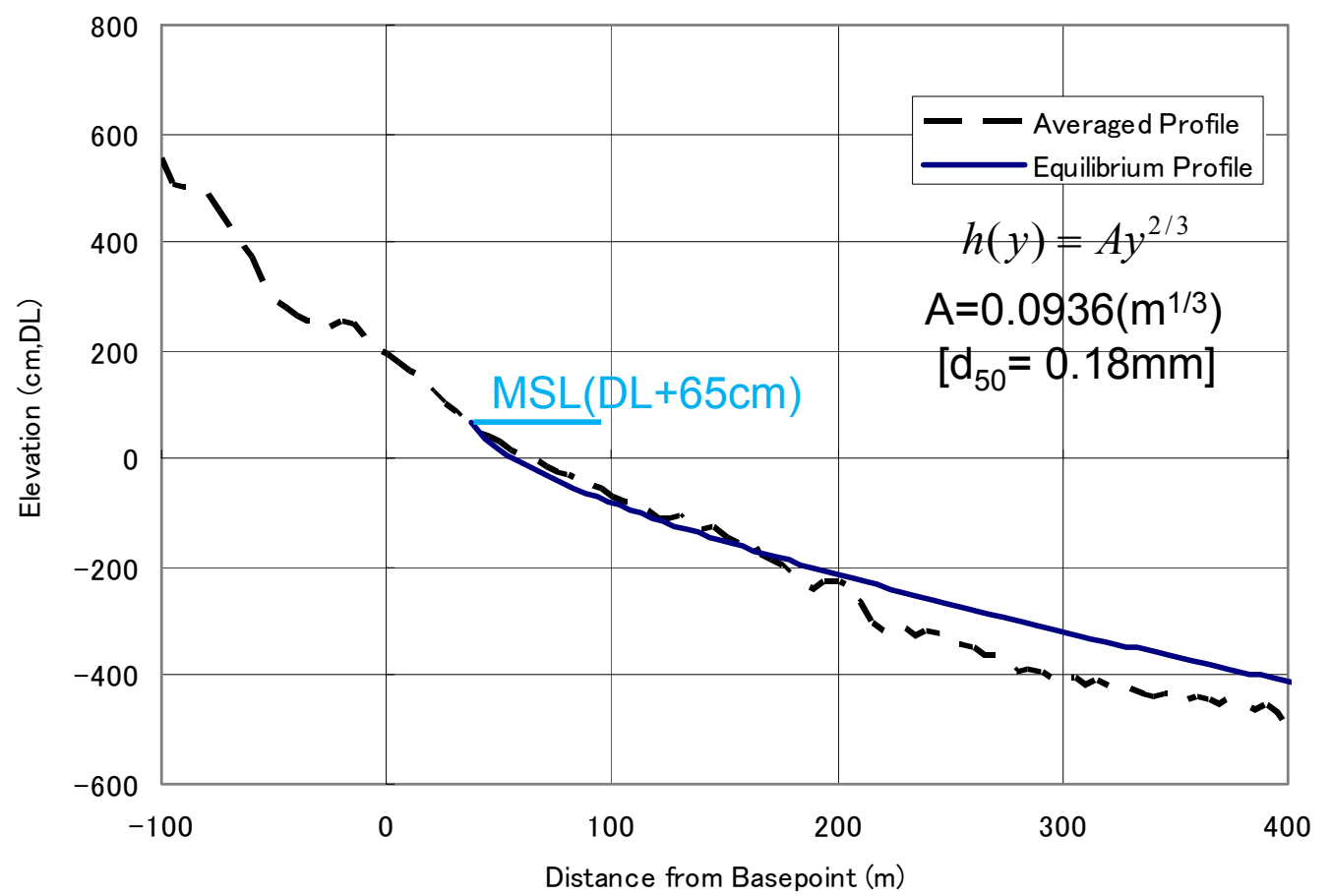

Figure 9. Comparison of equilibrium beach profile and averaged beach profile

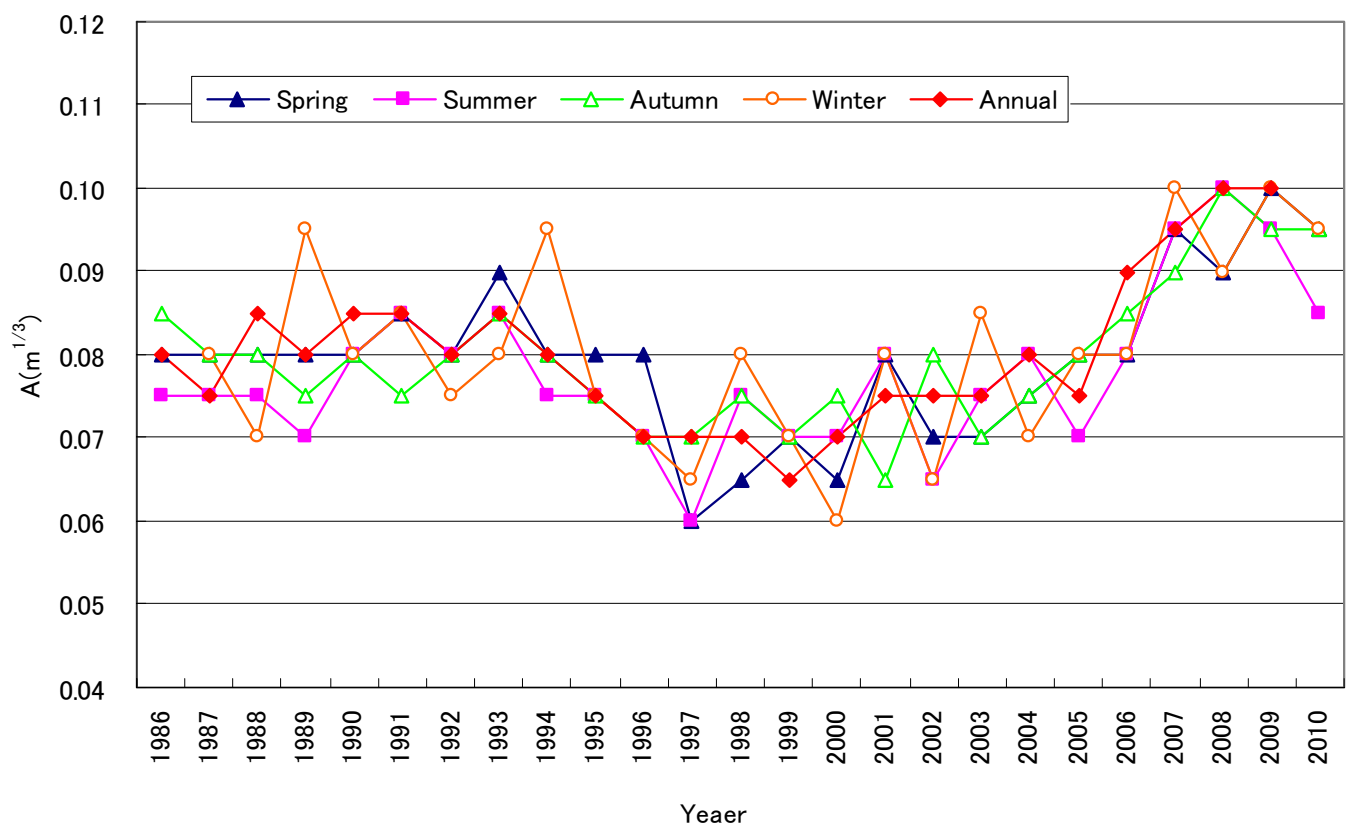

Figure 10. Seasonal change in cross-sectional area 


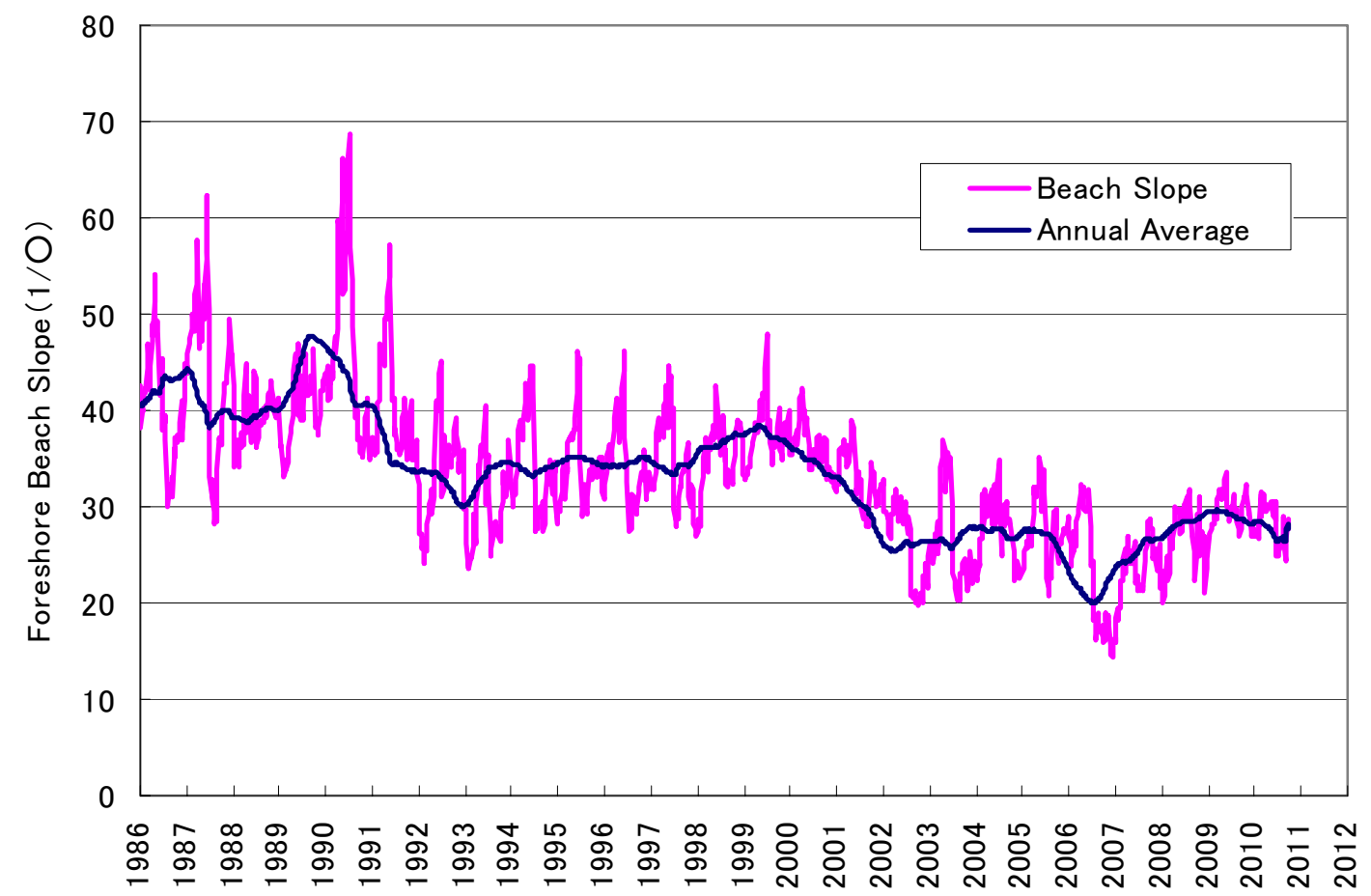

Figure 11. Time-series of beach slope

Figure 11 shows the time-series of beach slope above M.S.L., which is defined by the averaged beach slope above the M.S.L. The trend of the beach slope is contrary to the A value. This means the beach slope above M.S.L. and beach profile below M.S.L. has the opposite trend.

\section{BEACH PROFILE CHANGE ESTIMATION}

In this study, two approaches are applied to estimate the influences of wave condition change. As the short-term model, CSHORE (Kobayashi et al, 2008, 2010) is selected. On the other hand, as the mid-long term model, equilibrium beach profile theory introduced wave condition.

\section{Numerical Simulation approach}

The numerical model CSHORE has been developed by Kobayashi et al. (2009). This model consists of the following components: a combined wave and current model based on time-averaged continuity, cross-shore and longshore momentum, wave action, and roller energy equations; a sediment transport model for suspended sand and bedload; a permeable layer model to account for porous flow and energy dissipation; and a probabilistic model for an intermittently wet and dry zone for the purpose of predicting wave overwash and structural damage progression. This model has been calibrated and verified using a large number of small-scale laboratory experiments. Furthermore, this model has been calibrated using laboratory overwash tests and field profiles.

In this study, the input parameters are specified within the previous calibrations. Table 1 summarizes the input used in this simulation.

\begin{tabular}{|c|c|}
\hline \multicolumn{2}{|c|}{ Table 1. Input parameters. } \\
\hline Suspended load parameter & 0.2 \\
\hline Bedload parameter & 0.012 \\
\hline Overtopping parameter & $1.3-1.8$ \\
\hline Breaker ratio & 0.8 \\
\hline Runup wire height $(\mathrm{m})$ & 0.05 \\
\hline
\end{tabular}




\section{Simulation Conditions}

The offshore forcing for this simulation is the time-series of waves and water level. Fortunately, there is long-term wave (Kashima port, NOWPHAS) and water level observation (Choshi fishery port) near this site. In this study, these offshore conditions are estimated for a severe storm which occurred in 2006. The simulation duration for calibration is 1 year in 1999. Figure 12 shows the time-series data of the wave and water level condition and Figure 13 shows the beach profile data during the calibration term. In summer, the wave condition was relatively clam and beach profile has accretion trend above D.L.0. On the other hand, the severe storm conditions (large wave and long period) in winter and then the beach profile has the bar deformation and eroded at near shore region.

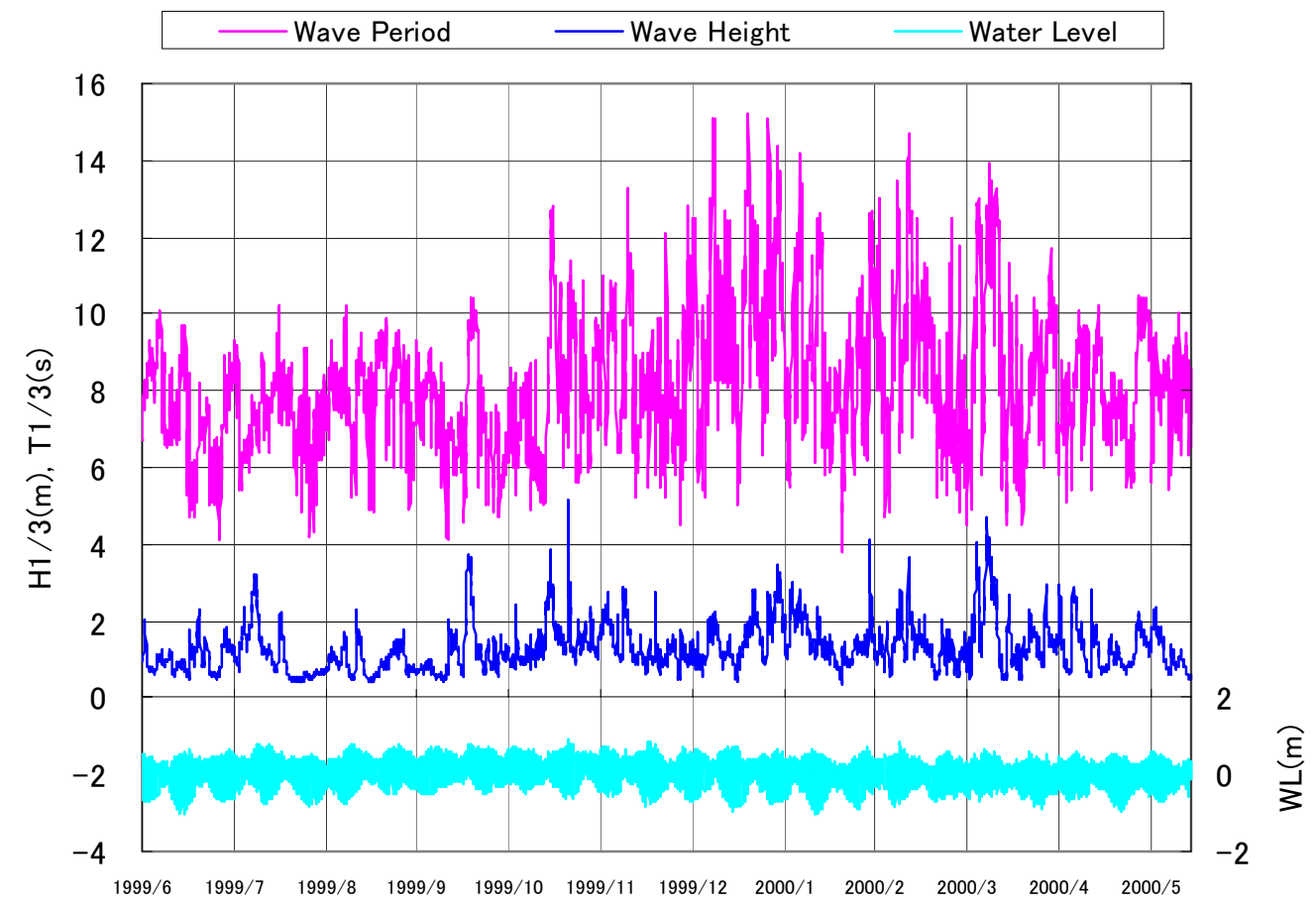

Figure 12. Time-series data of wave and water level

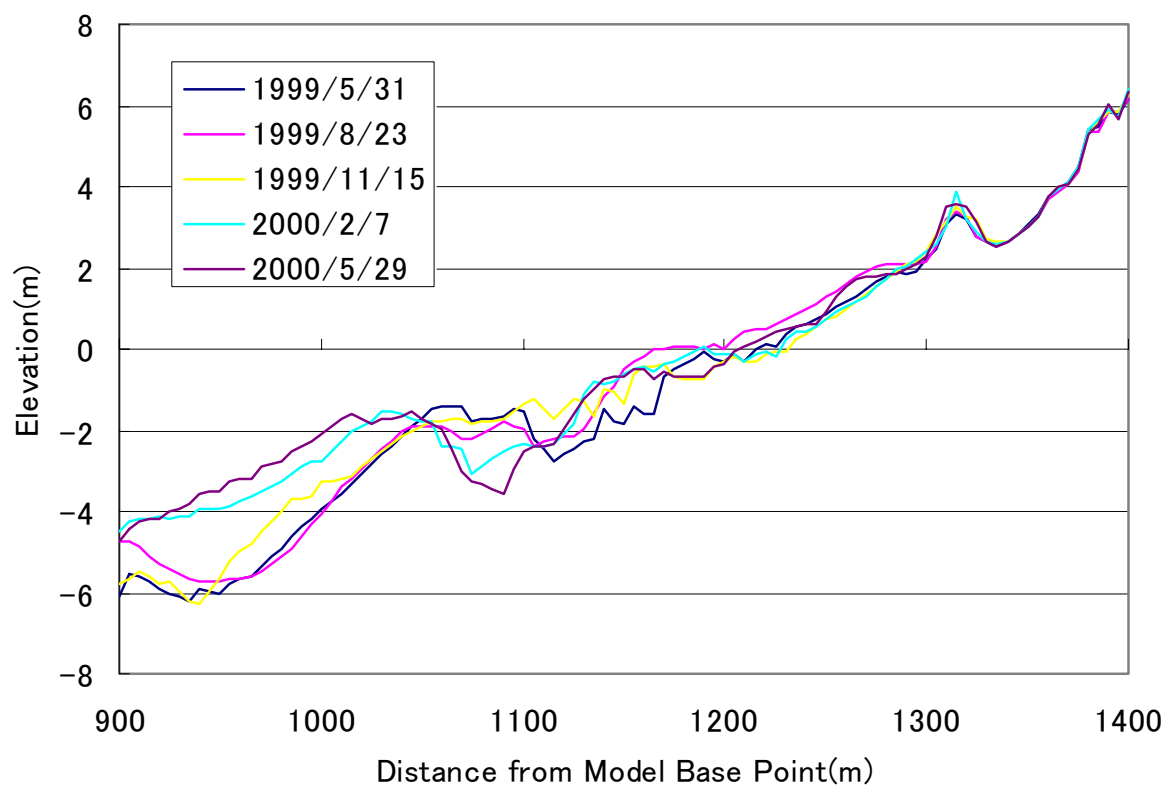

Figure 13. Beach profiles for model calibration 


\section{Simulation Results}

Table 2 describes the sediment conditions which is used in this calibration and Figure 14 shows the simulation results with initial profile, observed profile and calculated profile. The upper figure shows the result after summer and the lower figure shows the after summer and winter. As the result, the summer profile has the accretion trend as well as the observed profile, however, the offshore bar formation does not fit well. On the other hand, the winter result does not get reasonable fit even on the landward. This could occur because of the accumulation of uncertainties in this simulation.

\begin{tabular}{|c|c|}
\hline \multicolumn{2}{|c|}{ Table 2.Sediment Conditions. } \\
\hline Median grain size $(\mathrm{mm})$ & 0.18 \\
\hline Fall Speed $(\mathrm{m} / \mathrm{s})$ & 0.05 \\
\hline Sediment density $\left(\mathrm{kg} / \mathrm{cm}^{3}\right)$ & 2.65 \\
\hline
\end{tabular}
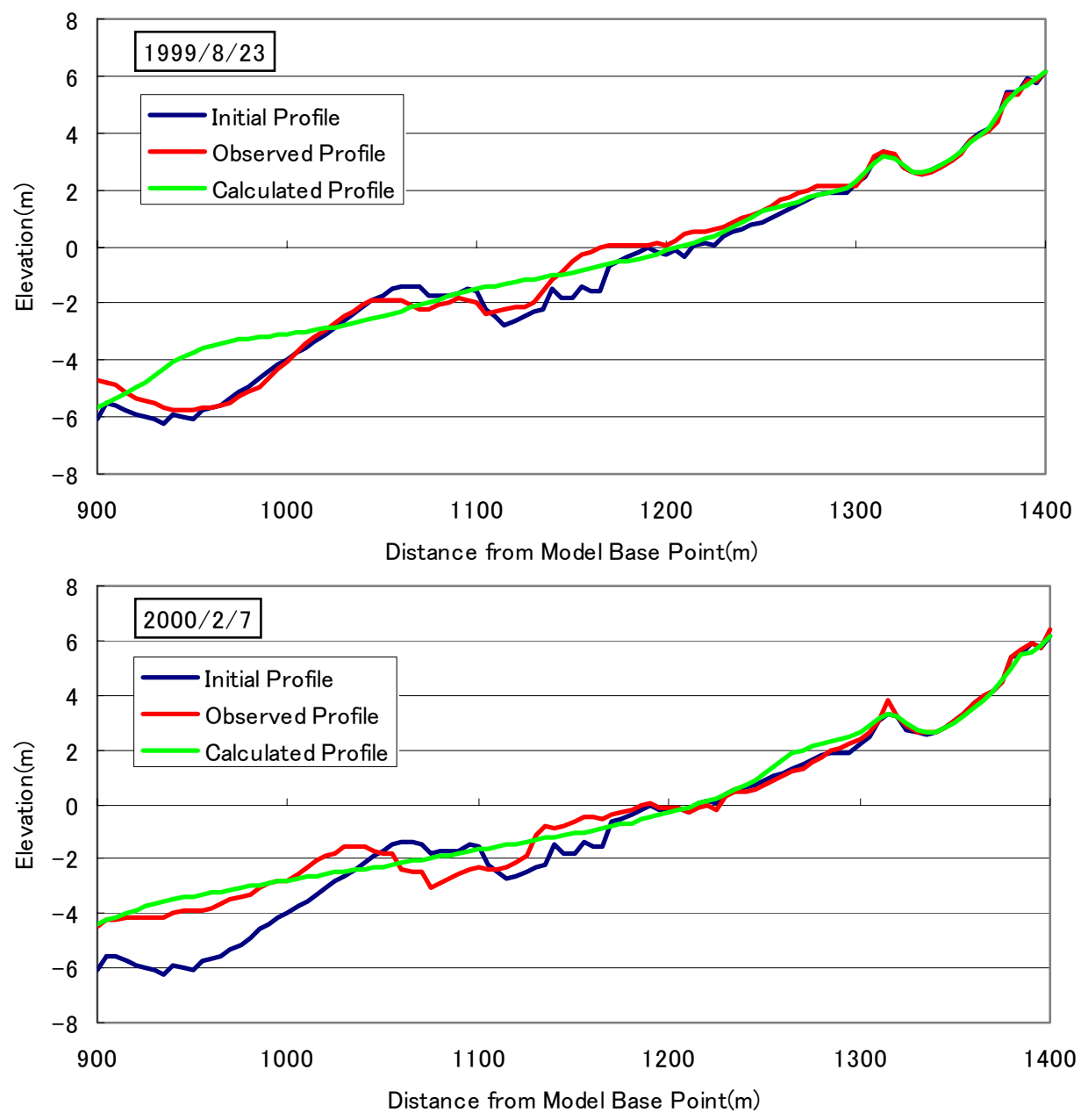

Figure 14. Simulation Result 


\section{Empirical formula approach}

As mentioned at the above paragraph, the coefficient $A$ of the equilibrium beach profile is related to the sediment parameter (i.e. median grain size) based on the assumption that the wave condition does not change. Therefore, in order to consider the influences of wave condition change, some wave parameters are introduced into the equilibrium beach profile theory. The theory is expressed by the wave energy dissipation theory with linear wave theory and the equilibrium beach profile is expressed with the uniform energy dissipation per unit volume for a given grain size $\mathrm{d}, D *(d)$ by :

$$
h(y)=\left(\frac{24 D_{*}(d)}{5 \rho g \sqrt{g} \kappa^{2}}\right)^{2 / 3} y^{2 / 3}=A y^{2 / 3}
$$

where, $y$ is the distance from shoreline, $h(y)$ is the local water depth at $y$ position, $\rho$ is the density of water, $g$ is the acceleration of gravity, and $\kappa$ is the breaking index, which is about 0.8 .

According to Larson and Kraus (1989), the uniform energy dissipation is given with the breaking model derived by Dally et al. (1985) by :

$$
D_{*}(d)=\frac{K}{8} \rho g \sqrt{\frac{g H_{b}}{\kappa}}\left(\kappa^{2}-\gamma^{2}\right)
$$

where, $H_{b}$ is the breaking wave height, $K$ is the an empirical constant taken as 0.17 , and $\gamma$ is the relationship between the stable energy flux and the stable wave height taken as about 0.4 in general.

Finally, equation (2) is substitute into equation (1), the A value is expressed by :

$$
A=\left(\frac{3 K}{5 \kappa^{2}} \sqrt{\frac{H_{b}}{\kappa}}\left(\kappa^{2}-\gamma^{2}\right)\right)^{2 / 3}
$$

In this study, this new equation is verified by using the recommended A value by Dean et al (2001). Figure 15 shows the relationship between the breaking wave height and A value. As the result, the greater grain size, the larger breaking wave height. However, if the grain size is fine, the breaking wave height becomes small. Therefore, when this equation is applied to the field data, it is hard to determine the wave condition.

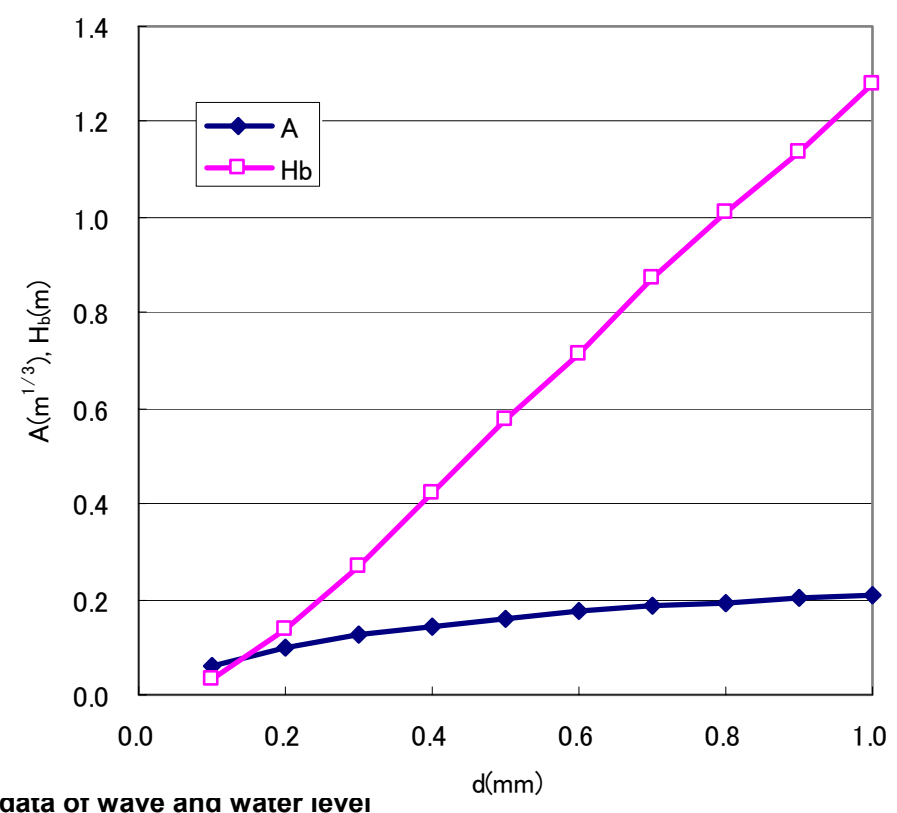

Figure 15. Time-series aata or wave and water Ieve 


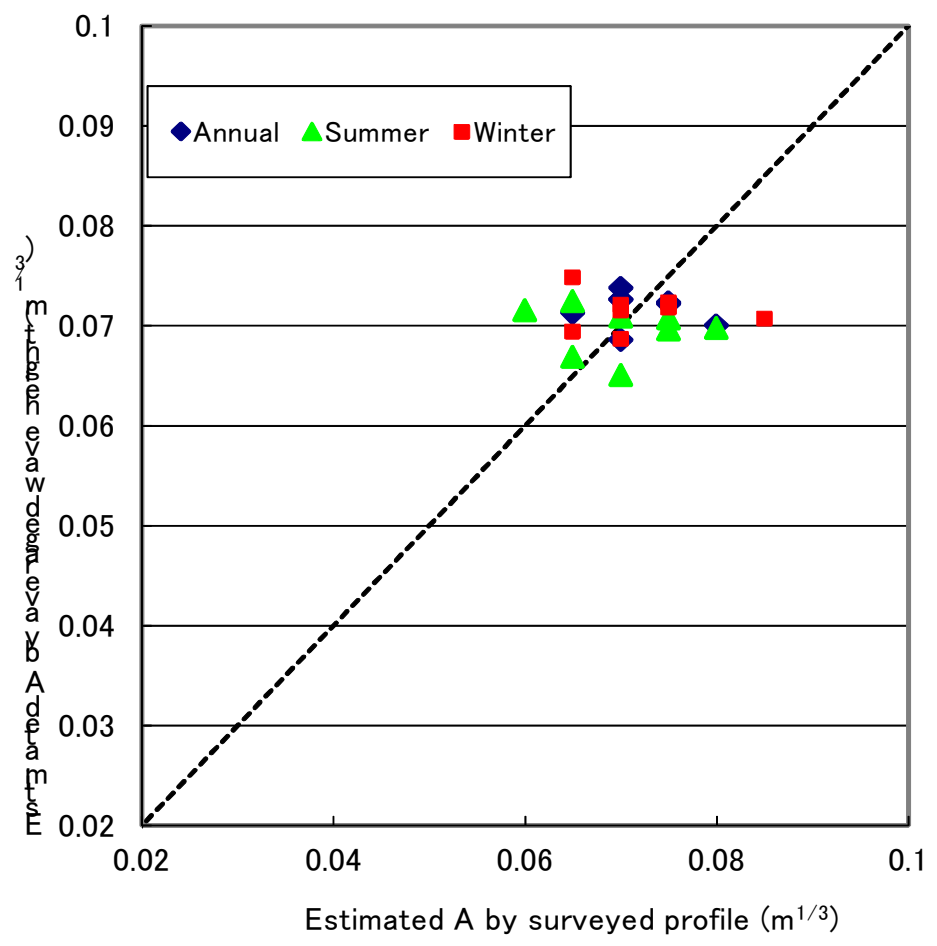

Figure 16. Relationship between the estimated $A$ value by surveyed profile and wave data

Moreover, the validation of the equation (3) is conducted by using the field data. In this study, the breaking wave height is treated as the energy averaged wave height. Figure 16 describes the relationship between the estimated A value by surveyed profile and wave data. As the result, the energy average wave height does not give good agreement with the A value in equilibrium beach profile. This could be because the introduced assumptions have some problems for estimating equilibrium beach profile.

\section{CONCLUSIONS}

Based on the mid-long term surveyed beach profile data at Hazaki coast, the mid-long term change on beach profile and the relationship between beach profile and wave condition are investigated in this study. Moreover, in order to estimate the influences of wave condition change, the short-term model and the mid-long term model are applied. The main conclusions are mentioned in the followings.

(1) The assessment of future change of beach profile has been introduced based on wave information. (2) The volumes below and above MSL has similar trend, but recently that below the MSL has decreasing trend. (3) The trends of beach slope above MSL and A value below MSL may has relationship. (4) In short-term model, it is difficult to apply for long-term beach profile because of accumulation of uncertainties from bar formation especially. (5) In mid-long term model, the effect of the wave can be introduced in the equilibrium beach profile, however the energy average wave height does not give good agreement with the A value in equilibrium beach profile.

\section{ACKNOWLEDGMENTS}

We would like to express appreciation to the efforts of Program for Generation of Climate Change Risk Information supported by Ministry of Education, Culture, Sports, Science and Technology, Japan and Grant-in-Aid for Scientific Research, Japan. 


\section{REFERENCES}

Bruun P. 1962. Sea Level Rise as a Cause of Shore Erosion. J. Waterway, Port, Coastal and Ocean Eng., ASCE, 88,117.

Dally, W. R. R. G. Dean and R. A. Dalrymple. 1985. Wave height variation across beaches of arbitrary profile, J. Geophys. Res. 90(C6), pp11917-11927.

Dean, R.G. 1977. Equilibrium Beach Profiles: U.S. Atlantic and Gulf Coasts, Department of Civil Engineering, Ocean Engineering Report No. 12, University of Delaware.

Dean, R.G., T.L. Walton, and D.L.Kriebel, 2001. Cross-shore Sediment Transport, Coastal Engineering Manual, US Army Coastal \& Hydraulics Laboratory.

Kobayashi, N., A. Payo, and L. Schmied. 2008. Cross-shore Suspended Sand and Bed Load Transport on Beaches. Journal of Geophysical Research, 113, C07001, doi: 10.1029/2007JC004203.

Kobayashi, N., A. Farhadzadeh, and J.A. Melby. 2010. Wave Overtopping and Damage Progression of Stone Armor Layer. J. Waterway, Port, Coastal and Ocean Eng., 136(5), 257-265.

Kuriyama, Y. and M. Banno, and T. Suzuki. 2012. Linkages among interannual variations of shore line, wave and climate at Hasaki, Japan, J. Geophysical Research Letters. Vol.39 L06604, doi:10.1029/2011GL050704.

Larson, M. and N.C. Kraus. 1989. SBEACH: Numerical Model for Simulating Strom Induced Beach Change, U.S..Army Corps of Engrs., CERC, Tech Rpt. CERC-89-9.

Mori, N. R. Iwashima, T. Yasuda, H. Mase, T. Tracey. 2009. Projection of Global Winds and Waves under Global Warming Scenario, Journal of JSCE, Ser. B2 (Coastal Engineering), Vol.65, pp.1271-1275. (in Japanese)

Mori, N. T. Shimura, T. Yasuda, H. Mase. 2010. Projection of Extreme Waves under a Global Warming Scenario. Journal of JSCE, Ser. B2 (Coastal Engineering), Vol.66, pp.1231-1235. (in Japanese)

Suzuki T., and Y. Kuriyama. 2008. Relationships between shoreline change rate, wave energy flux and longshore current velocity in long-term shoreline change. Journal of JSCE, Ser. B, Vol.64, No.4 pp.280-290. (in Japanese) 